\title{
Phage Selection of Chemically Stabilized $\alpha$-Helical Peptide Ligands
}

\author{
Philippe Diderich, ${ }^{\dagger}$ Davide Bertoldo, ${ }^{\dagger}$ Pierre Dessen, ${ }^{\dagger}$ Maola M. Khan, ${ }^{\dagger}$ Irene Pizzitola, ${ }^{\S}$ Werner Held, ${ }^{\S}$ \\ Joerg Huelsken, ${ }^{\ddagger}$ and Christian Heinis $* \dagger$ \\ ${ }^{\dagger}$ Institute of Chemical Sciences and Engineering, Ecole Polytechnique Fédérale de Lausanne, CH-1015 Lausanne, Switzerland \\ ${ }^{\ddagger}$ Swiss Institute for Experimental Cancer Research (ISREC), Ecole Polytechnique Fédérale de Lausanne, CH-1015 Lausanne, \\ Switzerland \\ ${ }^{\S}$ Ludwig Center for Cancer Research, Department of Oncology, University of Lausanne, CH-1066 Epalinges, Switzerland
}

\section{Supporting Information}

\begin{abstract}
Short $\alpha$-helical peptides stabilized by linkages between constituent amino acids offer an attractive format for ligand development. In recent years, a range of excellent ligands based on stabilized $\alpha$-helices were generated by rational design using $\alpha$-helical peptides of natural proteins as templates. Herein, we developed a method to engineer chemically stabilized $\alpha$-helical ligands in a combinatorial fashion. In brief, peptides containing cysteines in position $i$ and $i+4$ are genetically encoded by phage display, the cysteines are modified with chemical bridges to impose $\alpha$-helical conformations, and binders are isolated by affinity selection. We applied the strategy to affinity mature an $\alpha$-helical peptide binding $\beta$ catenin. We succeeded in developing ligands with $K_{\mathrm{d}}$ 's as low as 5.2 $\mathrm{nM}$, having $>200$-fold improved affinity. The strategy is generally

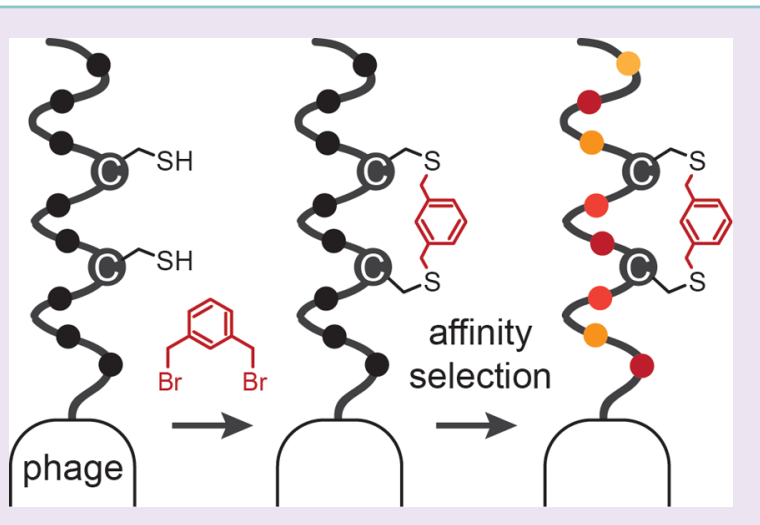
applicable for affinity maturation of any $\alpha$-helical peptide. Compared to hydrocarbon stapled peptides, the herein evolved thioether-bridged peptide ligands can be synthesized more easily, as no unnatural amino acids are required and the cyclization reaction is more efficient and yields no stereoisomers. A further advantage of the thioether-bridged peptide ligands is that they can be expressed recombinantly as fusion proteins.
\end{abstract}

$\mathrm{P}$ eptide helices are frequent mediators of key proteinprotein interactions that regulate important biological processes. Synthetic short $\alpha$-helical peptides thus appear ideal for the development of ligands. However, in aqueous solution, peptides with sequences of $\alpha$-helices do not have a stable threedimensional structure but populate multiple random-like structures. ${ }^{1}$ In the absence of structure, they do not bind efficiently the intended target, and they are susceptible to proteolytic degradation. Several approaches were developed for stabilizing $\alpha$-helical peptides, including the incorporation of covalent or noncovalent linkages between constituent amino acid side chains. ${ }^{2-6}$ Substantial helix stabilization has been achieved when the tether was positioned between the $i$ and either $i+4$ or $i+7$ residues in the peptide backbone. Such a linkage encompasses approximately one or two turns of an $\alpha$ helical peptide backbone and places the tethered side chains on the same side of the helix. Linkages include amide bonds to form lactams, ${ }^{7-9}$ disulfide bridges between pairs of $\mathrm{D}$ - and Lcysteines, ${ }^{10,11}$ hydrocarbon linkers formed by olefin metathesis, $^{12-16}$ triazole linkages formed between azides and alkynes, ${ }^{17-19}$ thioether bridges, ${ }^{9,20-22}$ and linkers generated by oxime formation ${ }^{23}$ or $S_{N} A r$ reaction. ${ }^{24,25}$ Most broadly applied is the ring-closing olefin metathesis producing hydrocarbon bridged $\alpha$-helical peptides, also named "stapled peptides." Stabilized helical peptide ligands were predominantly developed based on $\alpha$-helices from natural proteins. Many sequences were taken from $\alpha$-helices at the interface of protein complexes in order to generate inhibitors of protein-protein interactions. ${ }^{2,6}$ The first hydrocarbon-stapled peptides, the growth-hormone-releasing hormone analog ALRN-5281, and the p53 reactivator ALRN-6924 entered phase 1 clinical trials recently.

The development of chemically stabilized $\alpha$-helical peptides by rational design is not trivial at all. The choice of an optimal position for introduction of the chemical linker and the type of linker are key in the development of good binders. Typically, several different chemically bridged $\alpha$-helical peptides are designed and experimentally tested in order to obtain a molecule with a good binding affinity. Herein, we proposed to improve the binding affinity of rationally designed $\alpha$-helical ligands by generating and screening large combinatorial libraries of stabilized $\alpha$-helical peptides using phage display. We envisioned to display on phage $\alpha$-helical peptides that contain two cysteine residues in positions $i$ and $i+4$ and to connect them with thiol-reactive, helix-stabilizing linkers.

Received: November 20, 2015

Accepted: March 1, 2016

Published: March 1, 2016 
Polypeptides displayed on the surface of the filamentous phage were previously chemically modified via cysteine side chains. ${ }^{26}$ For example, peptides containing three cysteines were reacted with the reagent 1,3,5-tris(bromomethyl)benzene (TBMB) to generate and screen combinatorial libraries of bicyclic peptides. ${ }^{27-29}$ Thiol-reactive compounds that stabilize $\alpha$-helical peptides via a linker between cysteines $i$ and $i+4$ were identified by Greenbaum and co-workers who tested 24 commercially available molecules. $^{21}$ The reagent that stabilized $\alpha$-helices best was $\alpha, \alpha^{\prime}$-dibromo- $m$-xylene (DBMB). Fairlie and co-workers showed that the $m$-xylene-thioether linker induced helicity in a penta-peptide. ${ }^{8}$ More helix-stabilizing thiol-reactive reagents were reported recently by Dawson ${ }^{20}$ and Chou. ${ }^{30}$ All these thiol-reactive reagents were applied to stabilize chemically synthesized $\alpha$-helical peptides, but not to evolve stabilized $\alpha$ helical peptides by phage display.

\section{RESULTS AND DISCUSSION}

We considered the following three thiol-reactive reagents as most suitable to bridge cysteines in peptides on the phage and to impose $\alpha$-helical conformations (Figure 1A). DBMB is related to the reagent $\mathrm{TBMB}$ that our laboratory had used extensively for evolving bicyclic peptide ligands by phage display. ${ }^{28}$ As indicated above, this reagent was reported to stabilize synthetic peptides in $\alpha$-helical conformations. ${ }^{8,21}$ Trans-1,4-dibromo-2-butene (TDBB) and cis-1,4-dichloro-2butene $(\mathrm{CDCB})$ both yield bridges that are isosteric to the allhydrocarbon linker that is broadly and successfully used for stapling peptides. We first applied DBMB, TDBB, and CDCB to the model peptide YGGEAAREACARECAARE (peptide-1) which has previously been described to exhibit a low degree of helicity as a linear peptide in solution and a high degree of helicity when stabilized by chemical bridges via the two cysteines. ${ }^{21} \mathrm{CD}$ spectrometry showed that peptide-1 formed $\alpha$ helical structures when cyclized with DBMB and CDCB but not when modified with TDBB (Figure 1B). For the modification of peptides displayed on the surface of a filamentous phage, mild reaction conditions needed to be applied in order to prevent inactivation of the phage. The reaction conditions reported by Greenbaum and Fairlie to cyclize synthetic peptides with $\mathrm{DBMB}^{8,21}$ and our conditions to cyclize peptides with CDCB were clearly deleterious to phage. We tested if the peptides could be modified at $30{ }^{\circ} \mathrm{C}$ in aqueous solution at $\mathrm{pH} 8$ containing $20 \%$ acetonitrile, conditions that previously proved to be well tolerated by the phage. $^{28,31}$ Indeed DBMB and CDCB modified the peptide at concentrations of $100 \mu \mathrm{M}$ under these conditions.

In order to assess if $\alpha$-helical peptides stabilized by a chemical bridge can be evolved by phage display, we chose to affinity mature an $\alpha$-helix binding to $\beta$-catenin. $\beta$-Catenin is a signal transducer in the Wnt signaling pathway; mutations and overexpression of this protein are associated with different types of cancer. ${ }^{32}$ Grossmann et al. had previously developed an $\alpha$-helical peptide ligand of $\beta$-catenin by rational design. ${ }^{13}$ They stabilized an $\alpha$-helix of Xenopus axin, which is interacting with $\beta$-catenin, using an all-hydrocarbon linker. The stapled peptide termed fStAx-3 bound $\beta$-catenin with a $K_{\mathrm{d}}$ of $60 \mathrm{nM}$ and thus around 100 -fold better than the parental linear peptide fAxWT ( $>5 \mu \mathrm{M} ;{ }^{13}$ Figure $\left.2 \mathrm{~A}\right)$. Grossmann et al. had improved the affinity by screening variants of the peptide in the absence of the hydrocarbon staple using phage display. Subsequent insertion of the staple yielded a $\beta$-catenin ligand with a $K_{\mathrm{d}}$ of $8 \mathrm{nM}$. While the affinity of the stapled peptide was successfully
A
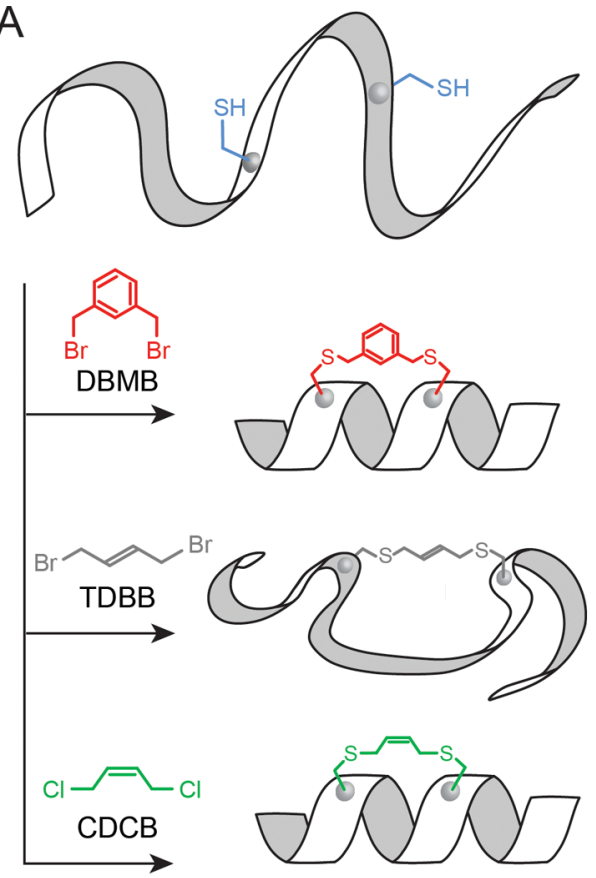

$\mathrm{B}$

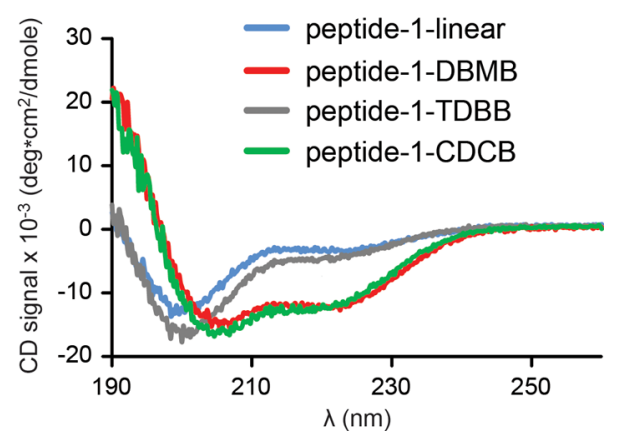

Figure 1. Bridging cysteines with chemical compounds to promote helix formation. (A) S-alkylation of a peptide containing two cysteines with three different chemical linkers. The type of peptide conformation imposed by the linker is indicated schematically. (B) $\mathrm{CD}$ spectra of peptide-1 recorded before or after reaction with the chemical bridges DBMB, TDBB, or CDCB.

enhanced with this approach, we reasoned that screening helical peptides in the presence of the stabilizing linker would have several advantages. Chemical linkers may impose a slight conformational change on the helix backbone, and beneficial interactions being evolved in phage selections may be forfeit to some extent if the linker is only inserted after the screen. Furthermore, chemical linkers may form contacts with the helix or the target protein. Such noncovalent interactions can only be optimized if the linker is present during the screen. In previous work with phage-selected bicyclic peptides, we learned that substitution of cyclization linkers post-phage selection is dramatically reducing the binding affinity of isolated peptide ligands. $^{33,34}$

As a starting point, we used the $\alpha$-helical peptide of axin (residues 467-482) and introduced cysteine residues in positions 471 and 475 (positions 6 and 10 of the peptide; GENPECILDCHVQRVM) that proved most suitable for peptide stapling in the work of Grossmann et al. The peptide was synthesized with an N-terminal fluorescein label (fAx-1linear; Figure 2A). CD spectrometric analysis showed that 


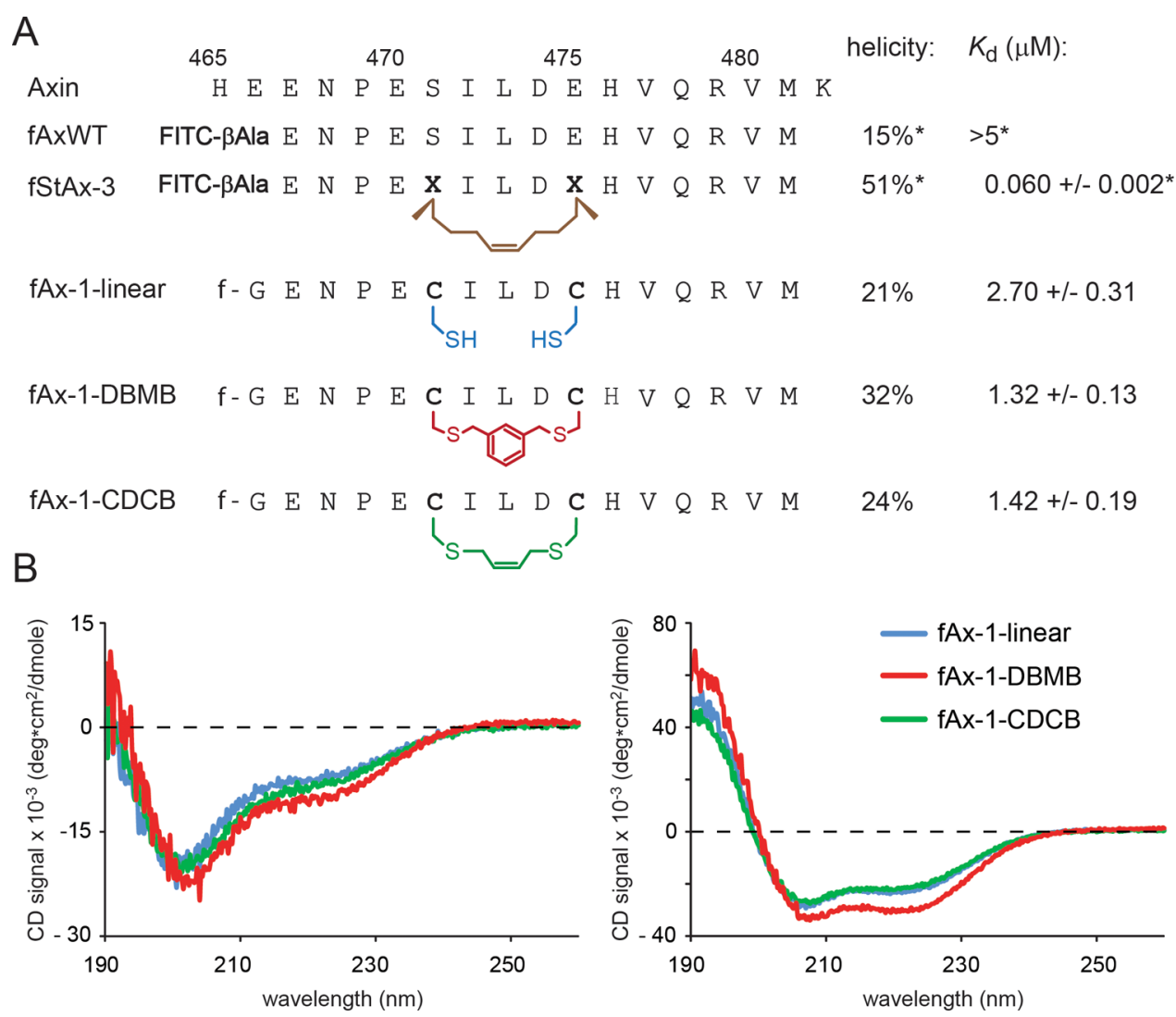

Figure 2. Characterization of axin-derived helix-stabilized peptides. (A) Sequences of $\beta$-catenin binding region of axin (axin numbering), axinderived peptide (fAxWT), axin-derived peptide "stapled" by olefin metathesis (X $=\alpha$-methyl, $\alpha$-alkenyl amino acids; fStAx-3), ${ }^{13}$ axin-derived peptide containing two cysteines (fAx-1-linear), and fAx-1 modified with DBMB or CDCB. Fluorescein was linked to the N-termini of the peptides via a $\beta \mathrm{Ala}$ or Gly linker. The \% helicity of the peptides in phosphate buffer at a $\mathrm{pH}$ of 7 is indicated. (B) $\mathrm{CD}$ spectra of axin-derived peptide before and after modification with DBMB or CDCB in phosphate buffer at a pH of 7 (left) or in 40\% TFE (right). *Data taken from Grossmann, T. et al. ${ }^{13}$

peptide cyclized with DBMB (fAx-1-DBMB) and CDCB (fAx1 -CDCB) formed only very weakly $\alpha$-helical conformations in phosphate buffer (Figure 2B, left panel). The fraction of helical peptide was slightly lower than the one of the previously reported hydrocarbon stapled peptide fStAx-3, having the same sequence but a hydrocarbon bridge (Figure 2A). In the presence of the helix-promoting solvent trifluoroethanol, the peptides folded efficiently into $\alpha$-helices (TFE, 40\%; Figure 2B, right panel). A binding assay based on fluorescence polarization showed that the peptides fAx-1-DBMB and $\mathrm{fAx}-1-\mathrm{CDCB}$ bound $\beta$-catenin with $K_{\mathrm{d}}$ 's of $1.32 \pm 0.13$ and $1.42 \pm 0.19$ $\mu \mathrm{M}$ and thus slightly better than the linear peptide $\mathrm{fAx}$-1-linear $\left(K_{\mathrm{d}}=2.70 \pm 0.31 \mu \mathrm{M}\right.$; Figure $2 \mathrm{~A}$ and Supporting Information Figure S1) but significantly worse than fStAx-3 $\left(K_{\mathrm{d}}=60 \mathrm{nM}\right)$. Having micromolar binding affinity, the peptides fAx-1-DBMB and $\mathrm{fAx}-1-\mathrm{CDCB}$ stabilized via cysteines offered much worse starting points for affinity maturation than the hydrocarbon stapled peptide fStAx-3 having a nanomolar binding constant. However, the compatibility with phage display promised the screening of enormously large combinatorial diversities.

We constructed phage display libraries based on the axin $\alpha$ helix that was mutated to different extents based on structural data using the axin/ $\beta$-catenin cocrystal structure ${ }^{35}$ and sequence-activity relationship data reported by Grossmann et al. (Figure $3 \mathrm{~A}) .^{13}$ In library 1 , most amino acid positions were "soft-randomized" so that in each position, the chance to retain the original amino acid was $34.3 \%$. Mutated genes were generated with degenerate primers and inserted into a phage vector for multivalent display of peptides via the $\mathrm{p} 3$ phage coat protein. A disulfide-free phage p3 was applied to prevent potential modification of cysteines in the phage coat. ${ }^{36}$ The cysteines of the purified phage were reduced and modified by incubation with $100 \mu \mathrm{M}$ DBMB or CDCB for $1 \mathrm{~h}$ at $30^{\circ} \mathrm{C}$. Three rounds of phage selection were performed wherein the quantity of immobilized $\beta$-catenin was gradually reduced in each round to increase the selection stringency $(2,0.2$, and 0.02 $\mu \mathrm{g})$. In the second and third rounds of panning, $3 \mu \mathrm{M}$ of Ax-1CDCB was added to eliminate weakly bound phage and thus to apply additional selection pressure. Peptides isolated after three rounds of selection shared high sequence similarity with the initial axin helix peptide, indicating that amino acids in many positions were already optimized for the new chemical bridges based on cysteine and the DBMB/CDCB linker (Figure 3B,D and Supporting Information Figures S2-S4). In peptides isolated from library 1 , seven of the soft-randomized positions had mutated back to the original amino acid, including the three amino acids of the central region "ILD" flanked by the cysteines. In the amino acid positions $11,12,13$, and 15, the following additional preferred residues were identified (Figure 3B,C and Supporting Information Figure S2). In the position of Val11, also Leu and Ile were preferred, and in position Met15, Trp was found as often as Met. In positions Gln12 and Arg13, amino acid preferences differed slightly in the selections with the linker DBMB (Gln in position 12, Arg/Ser in position 13) and $\mathrm{CDCB}$ (Gln/Ala/Asn in position 12, Arg in position 13). The three positions 1,2 , and 16 that were fully randomized in 


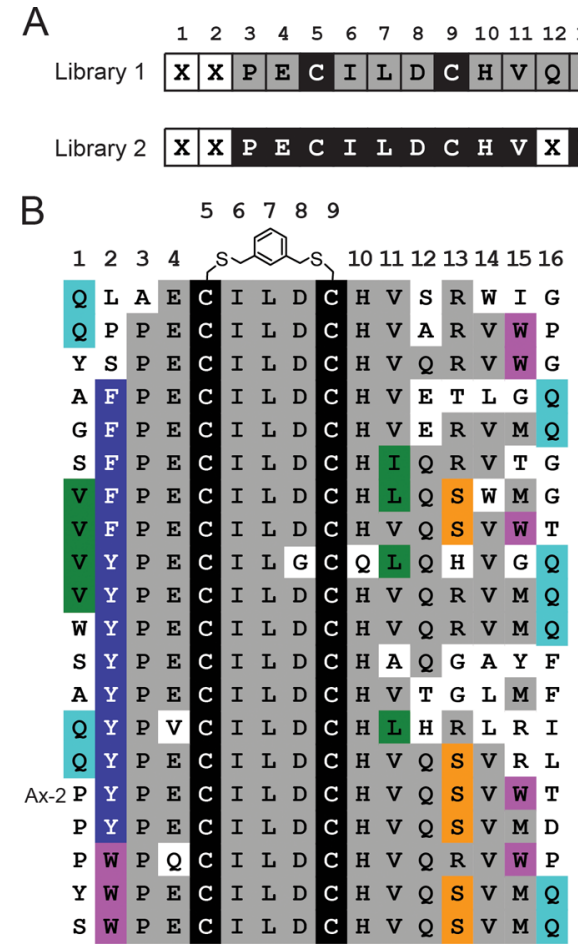

constant aa

$100 \%$ random aa

$34.3 \%$ indicated aa, $65.7 \%$ random

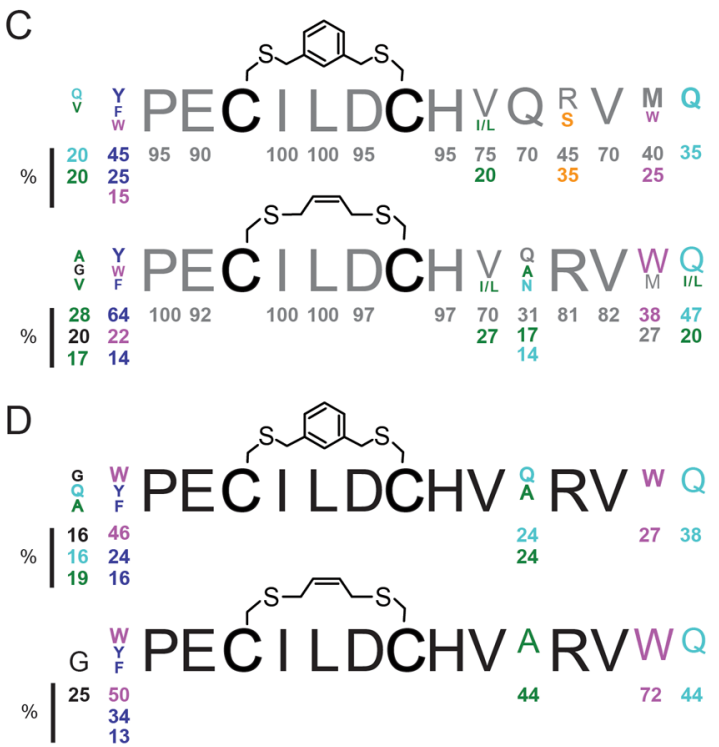

Figure 3. Affinity maturation of axin-derived peptide stabilized with DBMB or CDCB. (A) Format of the soft randomized library 1 and the partially randomized library 2 . Soft-randomized positions with a $34.3 \%$ chance of resulting in the wild-type amino acid are indicated with a letter on gray background. Fully randomized positions are shown as "X" on a white background, and fixed amino acids are shown on a black background. (B) Sequences of peptides isolated from library 1 modified with DBMB. All peptides sequenced are shown and amino acid similarities highlighted in color. (C and D) Consensus sequences of phage-selected peptides shown as logos. Peptides isolated from library 1 are shown in $\mathrm{C}$ and those isolated from library 2 in $\mathrm{D}$, respectively. The numbers show the abundance of the indicated amino acid in percent.

Table 1. $K_{\mathrm{d}}$ 's of Fluorescein-labeled Peptides Determined by Fluorescence Polarization ${ }^{a}$

\begin{tabular}{|c|c|c|c|c|c|c|}
\hline \multirow[b]{2}{*}{ peptide } & \multirow[b]{2}{*}{ library } & \multirow[b]{2}{*}{ sequence } & \multicolumn{4}{|c|}{$K_{\mathrm{d}}(\mathrm{nM}) \pm$ S.E. } \\
\hline & & & DBMB & $\mathrm{CDCB}$ & linear & $S-S$ \\
\hline$f A x-2$ & 1 & f-GPYPECILDCHVQSVWT & $36.4 \pm 2.6$ & $26.2 \pm 6.2$ & $1030 \pm 210$ & $>5000$ \\
\hline fAx-3 & 1 & f-GAYPECILDCHVARVQW & $13 \pm 0.8$ & $5.4 \pm 0.4$ & $38 \pm 7$ & $>5000$ \\
\hline $\mathrm{fAx}-4$ & 1 & f-GGYPECILDCHLQRVIL & $8.4 \pm 2.5$ & $7.1 \pm 1$ & $106 \pm 12$ & $>5000$ \\
\hline fAx-5 & 2 & f-GGWPECILDCHVQRVWQ & $16.1 \pm 1.7$ & $5.2 \pm 1.7$ & $167 \pm 23$ & $>5000$ \\
\hline$f A x-6$ & 2 & f-GGWPECILDCHVARVWS & $5.6 \pm 1.6$ & $7.9 \pm 0.9$ & $248 \pm 40$ & $>5000$ \\
\hline
\end{tabular}

${ }^{a}$ Standard deviations are indicated. Peptides fAx- 2 and fAx-5 were isolated in the phage selection with DBMB; peptides fAx-3, fAx-4, and fAx- 6 were isolated with CDCB.

library 1 converged to the amino acids Val/Gln/Gly/Ala (position 1), Tyr/Phe/Trp (position 2), and Gln (position 16), respectively. In the phage selection with library 2 , the isolated peptides shared high sequence similarity with the initial peptide too (Figure 3D and Supporting Information Figures S3 and S4). In the five fully randomized positions of these peptides, essentially the same amino acids were preferred as in the equivalent positions of peptides isolated from library 1 . The high sequence similarity of peptides isolated from library 1 and 2 with the two different reagents $\mathrm{DBMB}$ and $\mathrm{CDCB}$ suggested that the linkers most likely do not form direct contacts with amino acids of $\beta$-catenin. A comparison of the herein isolated peptides with those of Grossmann et al. that were isolated without stabilizing helical peptides prior to phage selection showed that similar amino acids evolved in positions 2 (Trp/ Tyr/Leu/Val by Grossmann et al. ${ }^{13}$ versus Trp/Tyr/Phe in this work) and 15 (Trp/Phe versus Trp/Met) and that different amino acids were preferred in positions $1,12,13$, and 16 .
We synthesized peptides from each selection with an $\mathrm{N}$ terminal fluorescein and measured their binding to $\beta$-catenin as (i) peptides stabilized with DBMB, (ii) peptides stabilized with CDCB, (iii) linear peptides, and (iv) peptides cyclized by a disulfide bridge (Table 1). The linker-stabilized peptides showed good binding with dissociation constants in the low nanomolar range (Supporting Information Figure S5). The best ligands $\mathrm{fAx}-3-\mathrm{CDCB}$ and $\mathrm{fAx}-5-\mathrm{CDCB}$ bound $\beta$-catenin with $K_{\mathrm{d}}$ 's of $5.4 \pm 0.4 \mathrm{nM}$ and $5.2 \pm 1.7 \mathrm{nM}$, respectively, which is $>200$-fold better compared to the starting point, the axin peptide stabilized by DBMB (fAx-1-DBMB, $K_{d}=1.32 \pm 0.13$ $\mu \mathrm{M})$. Analysis of the evolved peptides by $\mathrm{CD}$ spectrometry showed that the percentage of helicity in phosphate buffer at a $\mathrm{pH}$ of 7 is similar to the peptides fAx-1-DBMB and fAx-1$\mathrm{CDCB}$. This finding suggested that the large affinity improvement was not achieved through a better preorganization of the peptide in the $\alpha$-helical conformation but most likely through better interactions of the mutated amino acids with $\beta$-catenin. The different linkers had a substantial influence on the 
peptides' affinities. For example, peptide fAx-5 had a 3-fold better binding affinity with the CDCB linker $(5.2 \pm 1.7 \mathrm{nM})$ than with the DBMB linker $(16.1 \pm 1.7 \mathrm{nM})$. The linear peptides bound with much weaker affinities. For example, linear fAx- 6 bound with a 30 -fold weaker affinity than the same peptide stabilized by CDCB. The disulfide cyclized peptides did not bind at all to $\beta$-catenin at the highest concentration tested $(5 \mu \mathrm{M})$. The considerably different binding affinities of linear, DBMB-, and CDCB-cyclized peptides underscores that it is better to assay $\alpha$-helical peptides together with the stabilizing linker in the phage display selection. For the stapled peptides developed by Grossmann et al., ${ }^{13}$ the fluorescein label was reported to contribute to the binding. We synthesized one of the phage-selected peptides, $A x-4-C D C B$, without a fluorescein label and measured binding to $\beta$-catenin in a competition fluorescence polarization assay. Ax-4-CDCB bound much weaker than the fluorescein-labeled analogue $\mathrm{fAx}-4-\mathrm{CDCB}$ $\left(K_{\mathrm{d}}=150 \pm 10 \mathrm{nM}\right)$. Given the large contribution of the fluorescein moiety to the binding, the peptides may best be used with the fluorescein tag linked to the N-terminus in applications.

The affinity of the best $\beta$-catenin antagonists $\mathrm{fAx}-3-\mathrm{CDCB}$ and $\mathrm{fAx}-5-\mathrm{CDCB}$ is around 1.5 -fold better than the best hydrocarbon stapled peptide reported, StAx-34 $\left(K_{\mathrm{d}}=8 \pm 1\right.$ $\mathrm{nM})$. The affinity may be further improved by testing alternative amino acids in positions that converged to more than one preferred amino acid. The isolated peptides bound the paralogous protein $\gamma$-catentin (69\% sequence identity) with only weak affinity $\left(K_{\mathrm{d}}\right.$ 's higher than $400 \mathrm{nM}$ ), showing that the affinity maturation yielded highly selective binders (Supporting Information Table 1).

An important advantage of the newly evolved $\beta$-catenin binders compared to StAx-34 is the easy chemical synthesis: no non-natural amino acids are required, and the alkylation of thiols with the two commercially available linkers, DBMB and $\mathrm{CDCB}$, is a clean and nearly quantitative chemical reaction. The stabilized peptides were produced in this work by reacting crude peptide with $\mathrm{DBMB}$ or $\mathrm{CDCB}$ for $1.5 \mathrm{~h}$ and subsequent purification in a single round of RP-HPLC. Another advantage of the chemical reaction based on $\mathrm{DBMB}$ or $\mathrm{CDCB}$ is that a single product is formed. This is in contrast to the olefin metathesis reaction used to produce the hydrocarbon stapled peptides, in which reaction of two alkene groups yields the cis and trans isomers. Yet another strength of the novel linkerstabilized $\alpha$-helical peptides is their access to recombinant production. The $\alpha$-helical peptides can be expressed as fusion proteins and simply modified with the chemo-selective reagents $\mathrm{DBMB}$ and $\mathrm{CDCB}$. For example, they may be expressed as fusion with albumin or antibody $\mathrm{Fc}$ fragments to achieve a long circulation time of the peptides in vivo. We previously showed that cysteine-rich peptides expressed as Fc fusion can be cyclized efficiently with TBMB, a reagent having similar structure and reactivity as DBMB. ${ }^{37}$

In conclusion, we present a novel strategy that allows screening of combinatorial libraries comprising billions of stabilized $\alpha$-helical peptides by phage display. The strategy was enabled by the identification of two chemical linkers, DBMB and $\mathrm{CDCB}$, which can efficiently cyclize peptides on the surface of filamentous phage without damaging the phage particle, and stabilize peptides in their $\alpha$-helical conformation. In a proof-ofconcept study, we improved the affinity of peptides binding $\beta$ catenin more than 200 -fold to generate ligands with single-digit nanomolar binding constants. The stabilized $\alpha$-helical ligands can easily be chemically synthesized with building blocks being commercially available. Furthermore, the peptides can be expressed as fusion with proteins and stabilized with the linker postexpression.

\section{ASSOCIATED CONTENT}

\section{S Supporting Information}

The Supporting Information is available free of charge on the ACS Publications website at DOI: 10.1021/acschembio.5b00963.

Table 1: Binding of phage-selected peptides to $\gamma$-catenin. Figure S1: Fluorescence polarization experiment with fAx-1 peptides. Figure S2: Peptides isolated from library 1 after modification with CDCB. Figure S3: Peptides isolated from library 2 after modification with DBMB. Figure S4: Peptides isolated from library 2 after modification with CDCB. Figure S5: Fluorescence polarization experiments with phage-selected peptides. (PDF)

\section{AUTHOR INFORMATION}

\section{Corresponding Author}

*E-mail: christian.heinis@epfl.ch.

\section{Funding}

National Competence Center for Biomolecular Imaging (NCCBI; Ph.D. fellowship to P.D.), Swiss National Science Foundation (Sinergia grant 136245 to J.H, W.H., and C.H.), NCCR Chemical Biology of the Swiss National Science Foundation (instrument grant to C.H.)

\section{Notes}

The authors declare no competing financial interest.

\section{ACKNOWLEDGMENTS}

The financial contributions from the National Competence Center for Biomolecular Imaging (NCCBI; Ph.D. fellowship to P.D.) and the Swiss National Science Foundation (Sinergia grant 136245 to J.H, W.H., and C.H.) are gratefully acknowledged. J.H. holds the chair for Signal Transduction in Oncogenesis sponsored by Debiopharm. The work was in part also supported by the NCCR Chemical Biology.

\section{REFERENCES}

(1) Andrews, M. J. I., and Tabor, A. B. (1999) Forming stable helical peptides using natural and artificial amino acids. Tetrahedron 55, 11711-11743.

(2) Azzarito, V., Long, K., Murphy, N. S., and Wilson, A. J. (2013) Inhibition of alpha-helix-mediated protein-protein interactions using designed molecules. Nat. Chem. 5, 161-173.

(3) Cheng, R. P., Gellman, S. H., and DeGrado, W. F. (2001) betapeptides: From structure to function. Chem. Rev. 101, 3219-3232.

(4) Garner, J., and Harding, M. M. (2007) Design and synthesis of alpha-helical peptides and mimetics. Org. Biomol. Chem. 5, 3577-3585.

(5) Henchey, L. K., Jochim, A. L., and Arora, P. S. (2008) Contemporary strategies for the stabilization of peptides in the alphahelical conformation. Curr. Opin. Chem. Biol. 12, 692-697.

(6) Walensky, L. D., and Bird, G. H. (2014) Hydrocarbon-Stapled Peptides: Principles, Practice, and Progress. J. Med. Chem. 57, 6275.

(7) Bracken, C., Gulyas, J., Taylor, J. W., and Baum, J. (1994) Synthesis and Nuclear-Magnetic-Resonance Structure Determination of an Alpha-Helical, Bicyclic, Lactam-Bridged Hexapeptide. J. Am. Chem. Soc. 116, 6431-6432.

(8) de Araujo, A. D., Hoang, H. N., Kok, W. M., Diness, F., Gupta, P., Hill, T. A., Driver, R. W., Price, D. A., Liras, S., and Fairlie, D. P. 
(2014) Comparative alpha-Helicity of Cyclic Pentapeptides in Water. Angew. Chem., Int. Ed. 53, 6965-6969.

(9) Houston, M. E., Campbell, A. P., Lix, B., Kay, C. M., Sykes, B. D., and Hodges, R. S. (1996) Lactam Bridge Stabilization of R-Helices: The Role of Hydrophobicity in Controlling Dimeric versus Monomeric R-Helices. Biochemistry 35, 10041-10050.

(10) Jackson, D. Y., King, D. S., Chmielewski, J., Singh, S., and Schultz, P. G. (1991) General Approach to the Synthesis of Short aHelical peptides. J. Am. Chem. Soc. 113, 9391-9392.

(11) Leduc, A. M., Trent, J. O., Wittliff, J. L., Bramlett, K. S., Briggs, S. L., Chirgadze, N. Y., Wang, Y., Burris, T. P., and Spatola, A. F. (2003) Helix-stabilized cyclic peptides as selective inhibitors of steroid receptor-coactivator interactions. Proc. Natl. Acad. Sci. U. S. A. 100, $11273-11278$

(12) Blackwell, H. E., Sadowsky, J. D., Howard, R. J., Sampson, J. N., Chao, J. A., Steinmetz, W. E., O'Leary, D. J., and Grubbs, R. H. (2001) Ring-closing metathesis of olefinic peptides: design, synthesis, and structural characterization of macrocyclic helical peptides. J. Org. Chem. 66, 5291-5302.

(13) Grossmann, T. N., Yeh, J. T. H., Bowman, B. R., Chu, Q., Moellering, R. E., and Verdine, G. L. (2012) Inhibition of oncogenic Wnt signaling through direct targeting of beta-catenin. Proc. Natl. Acad. Sci. U. S. A. 109, 17942-17947.

(14) Schafmeister, C. E., Po, J., and Verdine, G. L. (2000) An allhydrocarbon cross-linking system for enhancing the helicity and metabolic stability of peptides. J. Am. Chem. Soc. 122, 5891-5892.

(15) Stewart, M. L., Fire, E., Keating, A. E., and Walensky, L. D. (2010) The MCL-1 BH3 helix is an exclusive MCL-1 inhibitor and apoptosis sensitizer. Nat. Chem. Biol. 6, 595-601.

(16) Walensky, L. D., Kung, A. L., Escher, I., Malia, T. J., Barbuto, S., Wright, R. D., Wagner, G., Verdine, G. L., and Korsmeyer, S. J. (2004) Activation of apoptosis in vivo by a hydrocarbon-stapled $\mathrm{BH} 3$ helix. Science 305, 1466-1470.

(17) Cantel, S., Le Chevalier Isaad, A., Scrima, M., Levy, J. J., DiMarchi, R. D., Rovero, P., Halperin, J. A., D’Ursi, A. M., Papini, A. M., and Chorev, M. (2008) Synthesis and conformational analysis of a cyclic peptide obtained via i to $i+4$ intramolecular side-chain to sidechain azide-alkyne 1,3-dipolar cycloaddition. J. Org. Chem. 73, 56635674.

(18) Kawamoto, S. A., Coleska, A., Ran, X., Yi, H., Yang, C. Y., and Wang, S. (2012) Design of triazole-stapled BCL9 alpha-helical peptides to target the beta-catenin/B-cell CLL/lymphoma 9 (BCL9) protein-protein interaction. J. Med. Chem. 55, 1137-1146.

(19) Lau, Y. H., de Andrade, P., Quah, S. T., Rossmann, M., Laraia, L., Skold, N., Sum, T. J., Rowling, P. J. E., Joseph, T. L., Verma, C., Hyvonen, M., Itzhaki, L. S., Venkitaraman, A. R., Brown, C. J., Lane, D. P., and Spring, D. R. (2014) Functionalised staple linkages for modulating the cellular activity of stapled peptides. Chem. Sci. 5, 1804-1809.

(20) Assem, N., Ferreira, D. J., Wolan, D. W., and Dawson, P. E. (2015) Acetone-Linked Peptides: A Convergent Approach for Peptide Macrocyclization and Labeling. Angew. Chem., Int. Ed. 54, 8665-8668.

(21) Jo, H., Meinhardt, N., Wu, Y., Kulkarni, S., Hu, X., Low, K. E., Davies, P. L., DeGrado, W. F., and Greenbaum, D. C. (2012) Development of alpha-helical calpain probes by mimicking a natural protein-protein interaction. J. Am. Chem. Soc. 134, 17704-17713.

(22) Muppidi, A., Wang, Z., Li, X., Chen, J., and Lin, Q. (2011) Achieving cell penetration with distance-matching cysteine crosslinkers: a facile route to cell-permeable peptide dual inhibitors of Mdm2/Mdmx. Chem. Commun. (Cambridge, U. K.) 47, 9396-9398.

(23) Haney, C. M., Loch, M. T., and Horne, W. S. (2011) Promoting peptide alpha-helix formation with dynamic covalent oxime side-chain cross-links. Chem. Commun. 47, 10915-10917.

(24) Brown, S. P., and Smith, A. B. (2015) Peptide/Protein Stapling and Unstapling: Introduction of s-Tetrazine, Photochemical Release, and Regeneration of the Peptide/Protein. J. Am. Chem. Soc. 137, 4034-4037.

(25) Spokoyny, A. M., Zou, Y. K., Ling, J. J., Yu, H. T., Lin, Y. S., and Pentelute, B. L. (2013) A Perfluoroaryl-Cysteine SNAr Chemistry
Approach to Unprotected Peptide Stapling. J. Am. Chem. Soc. 135, 5946-5949.

(26) Heinis, C., and Winter, G. (2015) Encoded libraries of chemically modified peptides. Curr. Opin. Chem. Biol. 26, 89-98.

(27) Angelini, A., Cendron, L., Chen, S. Y., Touati, J., Winter, G., Zanotti, G., and Heinis, C. (2012) Bicyclic Peptide Inhibitor Reveals Large Contact Interface with a Protease Target. ACS Chem. Biol. 7, $817-821$.

(28) Heinis, C., Rutherford, T., Freund, S., and Winter, G. (2009) Phage-encoded combinatorial chemical libraries based on bicyclic peptides. Nat. Chem. Biol. 5, 502-507.

(29) Baeriswyl, V., Calzavarini, S., Chen, S., Zorzi, A., Bologna, L., Angelillo-Scherrer, A., and Heinis, C. (2015) A Synthetic Factor XIIa Inhibitor Blocks Selectively Intrinsic Coagulation Initiation. ACS Chem. Biol. 10, 1861.

(30) Wang, Y., and Chou, D. H. (2015) A Thiol-Ene Coupling Approach to Native Peptide Stapling and Macrocyclization. Angew. Chem. 127, 11081.

(31) Olofsson, L., Ankarloo, J., and Nicholls, I. A. (1998) Phage viability in organic media: insights into phage stability. J. Mol. Recognit. $11,91-93$.

(32) Hahne, G., and Grossmann, T. N. (2013) Direct targeting of beta-catenin: Inhibition of protein-protein interactions for the inactivation of Wnt signaling. Bioorg. Med. Chem. 21, 4020-4026.

(33) Chen, S. Y., Bertoldo, D., Angelini, A., Pojer, F., and Heinis, C. (2014) Peptide Ligands Stabilized by Small Molecules. Angew. Chem., Int. Ed. 53, 1602-1606.

(34) Chen, S. Y., Morales-Sanfrutos, J., Angelini, A., Cutting, B., and Heinis, C. (2012) Structurally Diverse Cyclisation Linkers Impose Different Backbone Conformations in Bicyclic Peptides. ChemBioChem 13, 1032-1038.

(35) Xing, Y., Clements, W. K., Kimelman, D., and Xu, W. (2003) Crystal structure of a beta-catenin/axin complex suggests a mechanism for the beta-catenin destruction complex. Genes Dev. 17, 2753-2764.

(36) Kather, I., Bippes, C. A., and Schmid, F. X. (2005) A stable disulfide-free gene-3-protein of phage $\mathrm{fd}$ generated by in vitro evolution. J. Mol. Biol. 354, 666-678.

(37) Angelini, A., Diderich, P., Morales-Sanfrutos, J., Thurnheer, S., Hacker, D., Menin, L., and Heinis, C. (2012) Chemical Macrocyclization of Peptides Fused to Antibody Fc Fragments. Bioconjugate Chem. 23, 1856-1863. 